\title{
Stuckrad, Kocku von, Geschichte der Astrologie. Von den Anfängen bis zur Gegenwart
}

\section{Benoît Grévin}

\section{OpenEdition}

\section{Journals}

Édition électronique

URL : http://journals.openedition.org/ifha/6580

DOI : $10.4000 /$ ifha. 6580

ISSN : 2198-8943

\section{Éditeur}

IFRA - Institut franco-allemand (sciences historiques et sociales)

\section{Référence électronique}

Benoît Grévin, «Stuckrad, Kocku von, Geschichte der Astrologie. Von den Anfängen bis zur Gegenwart », Revue de I'IFHA [En ligne], Date de recension, mis en ligne le 01 janvier 2011, consulté le 22 septembre 2020. URL : http://journals.openedition.org/ifha/6580 ; DOI : https://doi.org/10.4000/ifha.6580

Ce document a été généré automatiquement le 22 septembre 2020.

(CIFHA 


\title{
Stuckrad, Kocku von, Geschichte der Astrologie. Von den Anfängen bis zur Gegenwart
}

\author{
Benoît Grévin
}

1 Cette synthèse concerne l'histoire de l'astrologie occidentale depuis sa naissance mésopotamienne jusqu'au XXIe siècle, en incluant le monde méditerranéen et l'Islam (avec une extension nord-américaine pour l'époque contemporaine). Elle est divisée en sept chapitres chronologiques (I. Introduction, p. 15-32 ; II. Des origines jusqu'à la formation d'un système d'interprétation complexe, p. 33-77 ; III. L'astrologie de l'antiquité, p. 78-158 ; IV. Un Moyen Âge plus bariolé qu'obscur, p. 159-206 ; V. La Renaissance, charnière vers la modernité, p. 207-241 ; VI. La fin de l'astrologie ? Révolutions scientifiques et explorations naturelles à l'époque des Lumières, p. 242-286 ; VII. Le développement de l'astrologie moderne, p. 287-370). Sa stratégie heuristique en agacera plus d'un. L'auteur, au nom d'un dépassement de conceptions prétendument révolues de l'histoire scientifique, pratique une approche ambigüe où la présentation de l'astrologie comme une herméneutique est contrebalancée par un appel constant à la nécessité d'appréhender l'évolution de la culture astrologique comme une partie de l'histoire des sciences (aussi bien que des religions) qui semble parfois servir de prétexte à une sorte de plaidoyer pro domo. Le propos oscille ainsi entre une présentation dépassionnée se rattachant à l'histoire des idées, non sans quelques percées vers l'histoire sociale, et une exposition « empathique » qui débouche parfois sur des développements pour le moins étranges. On s'étonne ainsi que des prophéties évidemment forgées ex eventu au sujet de Tibère ou Domitien soient présentées comme réelles (p. 105), sans la moindre précaution rhétorique (le cas arrive également dans d'autres chapitres...). Le choix du vocabulaire accentue également l'effet de malaise. $\mathrm{Ne}$ pouvait-on dire plus clairement, si on le pensait (?) que l'astrologie est une herméneutique dénuée en tant que telle de validité scientifique mais fascinante en tant qu'objet d'histoire culturelle lié tant aux pratiques religieuses qu'aux mutations scientifiques ? La lecture de la conclusion fait penser à une stratégie d'ambiguïté 
délibérée destinée à ne pas faire fuir des esprits rationalistes tout en confortant un lectorat d'un autre type.

2 À supposer que l'auteur reste dans les limites d'un travail de caractère strictement historique, la synthèse n'en est pas moins entachée de plusieurs imperfections. Le bas Moyen Âge s'arrête au XIIIe siècle, négligeant totalement la période 1300-1480, cruciale pour l'étude de l'impact culturel et social des pratiques astrologiques. Plus grave encore est le traitement infligé à l'Islam et l'Orient médiéval (p. 163-185), pour lequel l'adoption d'un discours multi-culturaliste n'empêche pas une série d'imprécisions en tout genre (Turfan situé en Mongolie, équation Harran-Ur, transcription aberrante amMa'mûn, etc.). Les autres chapitres, mieux documentés, contiennent quelques perles d'un éclat inquiétant. On nous informe ainsi p. 245 que le sac de Rome de 1527 fut provoqué par des mercenaires allemands qui se seraient rebellés contre la papauté après l'avoir défendue contre les troupes impériales (!). En résumé, on déconseillera la consultation d'un ouvrage dont les carences limitent la portée et qui laisse l'impression de pêcher en eaux troubles.

Benoît Grévin (CNRS, Laboratoire de médiévistique occidentale

4 de Paris) 